\title{
E-Commerce Internal Control Of Accounting Information Systems
}

\author{
Iskandar Muda ${ }^{1}$, Azizul Kholis ${ }^{1}$, Sonya Enda Natasha Pandia ${ }^{1}$ and Zainal Abidin Tarigan ${ }^{2}$ \\ \{iskandar1@usu.ac.id \} \\ ${ }^{I}$ Accounting Department, Faculty of Economics and Business, Universitas Sumatera Utara, Medan, \\ Indonesia \\ ${ }^{2}$ Universitas Negeri Medan, Indonesia
}

\begin{abstract}
Accounting information systems related to the company's business activities such as classifying, recording and communicating information as a result of the end to reach a good decision for the internal parties and external parties, along with the development of technology, the accounting information system switched from manual to computerized. Companies that use information systems computer-based accounting requires that internal controls are integrated to produce the maximum, thus helping companies to minimize risks that may occur in connection with the use of computer-based accounting information systems to business processes.
\end{abstract}

Keywords: on-line economy, Accounting Information System, E-Commerce, Internal Control

\section{Introduction}

E-Commerce is a describing the growing on-line economy. Since the Internet era, new companies have come into existence and are trading goods and services electronically. The ecommerce business may be for products sold directly to the consuming public or directly to other businesses (B2B is short for Business to Business trade). E-commerce is conducted with low overhead and in most cases without even storefronts.Simply speaking electronic business is any information system or application that empower business processes. This electronic communications technology includes: Internet, e-mail, E-books, database, and mobile phone. As with many terms with the 'e' prefix, it is useful to return to an original definition of the topic to more fully understand what e-marketing involves. The definition of marketing by the Chartered Institute of Marketing. "Marketing is the management process responsible for identifying, anticipating and satisfying customer requirements profitabily.

Technological developments at this time are full of everything that allows to be regulated thoroughly, and the system work manually began to shift in the presence of increasingly sophisticated technology (Yahya et al., 2018). Changes that occur manual system to be computerized on the SIA that changes the organizational structure, changes in storage data, changes in large volumes of data, changes to changes in information, changes in internal controls, changes in the direction of the accountant. Companies that have activities that require fast, accurate, and useful information at various levels of management for decision making. In the accounting system, certain controls are required to ensure that employees are doing their jobs well and secured by the way. Advantages of Accounting Information Systems (SIA) is a computerized speed increase the accuracy of data processing accounting information. SIA as an open system cannot be maintained as a system free of errors or fraud, so good internal control is a way for a system to protect itself from harm. Internal control is a process run by board of commissioners, management and other entity personnel designed to provide 
confidence in this: (1) the efficiency of financial reporting, (2) the effectiveness and efficiency of operations, and (3) Compliance with laws and regulations. Internal controls are made to minimize errors and risks of business transactions. Therefore, in the internal control there are policies and procedures appropriate for the company to achieve its goals and objectives (Arens, Elder and Mark, 2012). The internal control framework issued by COSO (the Committee on Sponsoring Organizations) has five components, namely (Arens, Elder and Mark, 2012):

1. Control environment, consists of actions, policies and procedures that reflect the attitude of top management, the directors and owners of the entity as a whole on internal control and its importance to the entity.

2. Risk assessment and analyze the risks relevant to the preparation of GAAP (Generally Accepted Accounting Principles).

3. Control activities are policies and procedures that help ensure that necessary action has been taken to address risks to achieve the goals of the entity.

4. The purpose of the accounting information and communication system of the entity is to initiate, record, process and report transactions conducted by that entity and maintain accountability of the related asset.

5. Monitoring activity is related to the continuous or periodic assessment of the quality of internal control by management to determine that the controls are operating as expected, and have been modified in accordance with changing conditions. Adequate internal controls are required to monitor the course of company activity.

This is intended to avoid the occurrence of things that can cause losses companies such as fraud, cheating, waste, and theft both from internal or external parties in assessing the company and to evaluate and take corrective action in anticipation of corporate weaknesses. Internal control system is expected to reduce the weaknesses, errors, and fraud that occurred. Based on the above description, accounting information system requires internal control, which means that the accounting information system and internal control should run together in a company.These reviews may be performed in conjunction with a financial statement audit, internal audit, or other form of attestation engagement.

\section{Literature Review}

Electronic commerce is an emerging concept that describes the process of buying and selling or exchanging of product, service and information via telecommunication and computer networks including the internet. (Kalakota and Robinson, 2001) define Electronic Commerce from various perspectives as:

1. From a communication perspective, E-commerce is the delivery of information, products/services, order and payments over telephone lines, computer networks or any other electronic means.

2. From a business process perspective, E-commerce is the use of technology towards the automation of business transaction and workflow.

3. From a service perspective, E-commerce is a tool that caters to the need of firms, consumers and management to cut down the transaction costs while improving the quality of goods/ services and increasing the speed of delivery.

4. From an online perspective, E-commerce provides the capabilityof buying and selling products and information on the internet and other online services.

The Electronics Trade Association simply defines E-Commerce as "Business business electronically". CommerceNet, an industry consortium, provides a more complete definition of "the use of computer networks as a means of business relationships". CommerceNet adds that 
in E-Commerce there is "the process of purchasing and selling services or products between two parties via the Internet or the exchange and distribution of information between two parties within a company using an intranet". While Amir Hartman in his book "Net-Ready" (Mirzaee and Ghaffari, 2018) more specifically defines E Commerce as "a kind of electronic business mechanism that focuses on individual business-based transactions using the Internet as a medium of exchange of goods or services between two institutions (B-to-B) as well as between institutions and direct consumers (B-to-C) " (Alsaad, Mohamad and Ismail, 2018). Some academics have also agreed to define E-Commerce as "one of the ways to improve the performance and mechanism of exchange of goods, services, information and knowledge by utilizing digital network equipment technology" (Arnold, 2018; Badewi et al., 2018). Ecommerce, electronic data interchange (EDI), and the Internet have dramatically changed business practices and record-keeping processes. Business implementation on the World Wide Web (WWW) has enabled organizations to connect with the outside world on-line and improve all aspects of their business(Lee and Tao, 2018; Perez-Estebanez, Urquía-Grande and Rautiainen, 2018). Business transactions in high tech environments are fully done with electronic form. Technology with low cost, high speed digital data transmission, using hardware that can generate information quickly and easily, and use software that can reduce, even in many cases can save time, eliminating the limitations of space and other limitations in obtaining information.

\section{Research Methods}

Descriptive methods is a research conducted with the main objective to objectively describe or describe a situation. This research design is used to solve or answer problems that are being faced in the current situation. Descriptive research also means research that is intended to explain individual phenomena or characteristics, certain situations or groups accurately. Literature study conducted by the author is by searching various written sources, in the form of books, archives, magazines, articles, and journals, or documents that are relevant to the problem being studied. So that the information obtained from this literature study is used as a reference to strengthen the existing arguments. Literature Study is a research conducted by researchers by collecting a number of book books, magazines related to research problems and objectives. This technique is carried out with the aim to reveal various theories that are relevant to the problems being faced /examined as reference material in the discussion of research results. This literature study was carried out by researchers after determining the research topic and determining the formulation of the problem, before plunging into the field to collect the necessary data.

\section{Result And Discussion}

The implementation of e-commerce within the company has several competitive advantages, namely (Vanneschi et al., 2018):

1. Productivity and cost reduction, E-commerce helps companies carry out value chain activities more effectively by helping companies engage in the integration of overall sales, production, and delivery processes electronically through bounds and times.

2. Speed, Information and knowledge can move freely within the company and its consumers, suppliers, and constituents. Managers can implement decisions faster. E-commerce can also reduce time to market and other cycle times to respond to implementation or anticipate business needs.

3. New opportunities and value creation, Business through the web can flourish because of the flexibility, focus, and initiative of entrepreneurs through global operations. A key benefit of 
global organizations is the ability to implement strategies on a wider scale, a globalized organization.

If look closely, there are basically 4 (four) types of relationships in the business world commonly woven by a company (Fingar and Aronica, 2001):

a) Relation with supplier (supplier);

b) Relationships with distributors;

c) Relationships with partners (partners); and

d) Relation with consumer (customer).

This section discusses the impact of e-commerce on changes in the role of accountants, audit risk assessments, internal controls, and the collection and validation of electronic audit evidence.

\subsection{Accounting Information System (AIS)}

According to (Vanneschi et al., 2018) AIS is a collection of organizational activities that are responsible for providing financial information and information obtained from data transactions for internal reporting purposes to managers for use in future control and planning and operations in the future and external reporting to shareholders, government, and other outside parties. From the definition can be concluded that the AIS is an activity input, process, and output data conducted by the company. The final results of the data processed by the SIA are intended as internal and external party reports to control the company.

\subsubsection{Mistakes And Risk In AIS}

The errors occurred in the AIS usually occurs by two because that is a deliberate errors and mistakes are not intentional. Unintentional errors generally occur in the process of data processing applications, such as you enter the code, any value that generally error is due to the inaccuracy. Deliberate mistakes, is cheating in the form of theft or misappropriation of the assets of the company. (Arens, Elder and Mark, 2012) describe some specific risks that occur in information technology systems include:

1. Risk on hardware and data a. Dependence on the ability of the proper functioning of hardware and software. b. Systematic errors versus random error. c. Unauthorized access. d. The loss of data.

2. An audit trail is reduced a. Audit trail visibility b. Reduced human involvement c. The absence of the traditional authorization

3. The need for IT experience and segregation of duties a. Segregation of duties reduced b. The need for IT experience, adding a computerized system risk is the risk of a general nature is that something that computerized systems can not function, resulting in the company's operations become dormant. Something that is meant to be a power interruption or network system.

\subsubsection{Control of Computer-Based Information System}

The types of controls used by the company to ensure the integrity of accounting information system:

1. General controls common controls designed to ensure that the entire computer system can function optimally and data processing can be carried out smoothly as planned. General controls can be done in the following way:

a. Preparation of security plan

b. Separation of duties in the functioning of the information system 
c. Preparation of project control information system

d. Physical access control

e. Login access control

f. Control data storage

g. Data transmission control

h. standard documentation

i. Minimize downtime information

j. Damage recovery plan

k. Protection against computer and network

1. control of the internet

2. The main purpose of the application control application controls is to assure the accuracy and validity of input, process and output of the application program. Application controls and general controls complement each other, so both are important and necessary, because the application control is much more effective if supported by a strong public control. If the application control is weak, then the output of the AIS will contain errors. Contains an error when used to make a decision, the decision will result in improper or misleading, and can affect the relationship between the company and its customers, suppliers and other external parties.

At AIS contained computerized input, process and output in data processing, need for internal control in the processing of these data in order to produce good data for the company describes as follows: 1 . Input Control input Control aims to ensure that the received data to be processed have been authorized, complete, free of fault, identified as data that can be read by machine (computer). 2. Process Control Process control aims to prevent errors that occur during the process of data entered into the computer. 3. Control Output Control output aims to ensure accuracy in processing the results and ensure that the party entitled to receive only the output. Input Control input control aims to ensure that the received data to be processed have been authorized, complete, free of errors, identified as data that can be read by machine (computer).

\subsection{Internal Control}

Computing technology related judgments including database management, networking, data communications (Guo et al., 2018) and auditing judgment including security issues. This action is undertaken by management to plan, organize, and direct performance for adequate action that provides reasonable assurance for the achievement of the objectives of meeting the objectives and objectives set for operations and programs, the use of resources economically and efficiently, securing resources, trust and integrity, and adherence to policies, planning, procedures, laws and regulations. This field includes policies and procedures that access to equipment, software, and data restricted to authorized users only. SAS no. 56 and 78 provide general guidelines for internal control frameworks in electronic data processing (EDP) environments (Hwang, Lin and Shin, 2018). Accounting control structure according to AICPA in SAS No. 3 divided into two, namely general control and application control.

\subsubsection{General Control}

General control is the overall control that impacts the electronic data processing environment. The objective is to establish a comprehensive control framework for electronic data processing activities and to provide a reasonable level of assurance that overall internal control objectives can be achieved. These general controls include: 


\section{Organizational Control and Operations}

Organizational and operational controls are implemented by segregating functions in the electronic data processing part and separating the electronic data processing part by itself with the data user part. In order to avoid confusion in the organization, it is necessary to describe the position. Electronic data processing departments within the organizational structure should have their own position in order to be independent. Independence is required for the electronic data processing department to serve all parties within the organization as needed in order to achieve the organization's overall objectives.

\section{Documentation Control}

Documentation can be regarded as written material or something that provides information about a subject. Documentation may contain descriptions, descriptions, flowcharts, lists, prints of computer results, and examples of objects from information systems. Documentation in accounting information systems are grouped into two parts:

a. Documentation stored in the accounting department.

1) Documentation of basic documents.

It is a documentation that contains a collection of basic documents as evidence of transactions used in the system.

2) Documentation of account list.

It is a documentation that shows information about the accounts used in the transaction. The list of accounts contains a list of account codes, account names, PDE Managers, System, analysts, Programmers, Compu Data Entry, Computer, Librarian Data Control, Group DBA, classification, as well as instructions from each account how the account is used.

3) Documentation of manual procedures.

Is a documentation that shows the flow of the basic document in the company. This documentation provides information on which parts prepare the basic document, the copy amount, which parts archive it and to which parts of the basic document should be sent.

b. Documentation in the PDE section

1) Documentation of procedures, may contain procedures to be performed in a given situation

2) Documentation system, shows the form of data processing system described in the system flowchart. In this documentation can be seen a description of the input used, the resulting output, the files used, news processing error reports and control lists for each system processing.

3) Program documentation, Illustrates the logic of the program in the form of a program flowchart (program flowchart), decision tables, and forms of program control.

4) Documentation of the operation, the operating documentation contains explanations of the ways and procedures of operating the program.

5) Data documentation, the data documentation contains the definitions of the data items in the database used by the information system.

Documentation can be regarded as written material or something that provides information about a subject. Documentation may contain descriptions, descriptions, flow charts, lists, computer prints, and examples of objects from information systems.

\section{Hardware Control.}


Hardware control is a control system already installed in a computer by the manufacturer. This control is intended to detect errors or malfunction of hardware. Hardware control can be Dual Read Check, Parity Check, Echo Check, Read After Check

4. Physical Security And Data Security Control

Computer and file protection should be made to avoid damage and fire.

5. Communication Control

Communication control is intended to handle errors during the process of transmitting data and to prevent data security during transmission of such data. This control covers two things, namely: (Marshall and Lambert, 2018)

1. Control of transmission errors. In a data transmission may occur unexpected interruptions, called noise. When there is noise, then the data will be transmitted error. These errors must be detectable and corrected.

2. Control of data transmission security. In transmitting data from one place to another there will be problems with respect to the security and confidentiality of transmitted data. To overcome and protect the security of the data, it is necessary to change its shape into a certain secret code.

\subsubsection{Application Control}

a) Control input has a purpose to ensure that the valid transaction data has been complete, collected all and free of errors before the processing process. Is an important control, because the input is wrong, the output will also be wrong. And the wrong input when it has passed the processing stage, will be difficult to detect. So the input data must be completely error-free.

b) Control is done when used media such as card plong, paper ribbon, magnetic tape and magnetic disk off-line.

c) Control at the data entry stage. Control at this stage in the form of checks that have been programmed in the application program and called programmed check (programmed check) (Mahindroo, Samalia and Verma, 2018). Controls in the programmed check can be Echo check, Existence check and Matching check.

\subsubsection{Processing Control}

The purpose of processing control is to prevent errors that occur during data processing done after the data entered into the computer. Error processing can occur because the application program used to process the data contains errors (Kasemsap, 2018). Errors that occur during the processing phase can be controlled by checking the process of the program. Computer programs are made in such a way that errors that occur during processing can be detected. Errors can then be corrected after processing is complete.

\subsubsection{Output Control}

Output which is a product of data processing can be presented in two main forms, namely in the form of hard copy and soft copy. In the form of hard copy is the most widely done is in the form of reports printed using the printer (printer) and in the form of soft copy is the most common form of display on the screen terminal.

In e-commerce business all transactions are done electronically and some accounting information systems owned by the company can also be accessed by outsiders. Customers can make a purchase order even look at the inventory owned by the company, so that it has an impact on its internal control. The impact of ecommerce on internal control poses a new problem on the validity of transactions, authorization of transactions and the security of 
corporate property. To minimize such risks and obtain good results, accounting information systems should be supplemented by internal controls, internal controls required as guidelines or limitations applied by the company to minimize risks that may occur with regard to the use of accounting information systems to achieve the goals of the company.

\section{Conclusions}

The company generally performs internal control over the input, process, and output of its business process activities, manual controls used include transaction authorization, supervision, task separation, accounting records, access control, and independent verification. Computerized controls are grouped into two general controls and application controllers. General controls relate to entities entirely, such as control over data centers while application control ensures system-specific integrity such as sales order processing, merchant debt, and payroll applications

\section{References}

[1] Alsaad, A., Mohamad, R. and Ismail, N. A. (2018) 'The contingent role of dependency in predicting the intention to adopt B2B e-commerce', Information Technology for Development. Routledge, pp. 1-29. doi: 10.1080/02681102.2018.1476830.

[2] Arens, A. A., Elder, R. J. and Mark, B. (2012) Auditing and assurance services: an integrated approach. Boston: Prentice Hall.

[3] Arnold, V. (2018) 'The changing technological environment and the future of behavioural research in accounting', Accounting \& Finance. John Wiley \& Sons, Ltd (10.1111), 58(2), pp. 315-339. doi: 10.1111/acfi.12218.

[4] Badewi, A. et al. (2018) 'ERP Benefits Capability Framework: Orchestration Theory Perspective', Business Process Management Journal2, 24(1), pp. 266-294.

[5] Fingar, P. and Aronica, R. (2001) Death of ' $e$ ' and the Birth of the Real New Economy: Business Models, Technologies and Strategies for the 21st Century. Florida: MeghanKiffer Press.

[6] Guo, Y. et al. (2018) 'Mobile e-commerce recommendation system based on multisource information fusion for sustainable e-business', Sustainability (Switzerland), 10(1). doi: 10.3390/su10010147.

[7] Hwang, Y., Lin, H. and Shin, D. (2018) 'Knowledge system commitment and knowledge sharing intention: The role of personal information management motivation', International Journal of Information Management. Pergamon, 39, pp. 220-227. doi: 10.1016/J.IJINFOMGT.2017.12.009.

[8] Kalakota, R. and Robinson, M. (2001) E-Business 2.0: Roadmap for Success. New Jersey: Addison Wesley Professional.

[9] Kasemsap, K. (2018) 'Enterprise Information Systems and Digital Marketing: Advanced Issues and Implications.', in E-Manufacturing and E-Service Strategies in Contemporary Organizations. Suan Sunan. IGI GLOBAL, pp. 53-71.

[10] Lee, Y.-L. and Tao, K.-C. (2018) 'The Barriers and Key Breakthrough Factors for Ecommerce Implementation for Small Agriculture Firms in Taiwan Rural Areas', in Proceedings of the 2nd International Conference on E-Society, E-Education and ETechnology - ICSET 2018. New York, New York, USA: ACM Press, pp. 94-97. doi: $10.1145 / 3268808.3268820$.

[11] Mahindroo, A., Samalia, H. V. and Verma, P. (2018) 'Information systems road map to enhance economic and operational reverse logistics performance', International Journal of Logistics Systems and Management, 29(2), p. 215. doi: 10.1504/IJLSM.2018.089172. 
[12] Marshall, T. E. and Lambert, S. L. (2018) 'Cloud-Based Intelligent Accounting Applications: Accounting Task Automation Using IBM Watson Cognitive Computing', Journal of Emerging Technologies in Accounting. American Accounting Association , 15(1), pp. 199-215. doi: 10.2308/jeta-52095.

[13] Mirzaee, S. and Ghaffari, A. (2018) 'Investigating the impact of information systems on knowledge sharing', Journal of Knowledge Management. Emerald Publishing Limited , 22(3), pp. 501-520. doi: 10.1108/JKM-08-2017-0371.

[14] Perez-Estebanez, R., Urquía-Grande, E. and Rautiainen, A. (2018) 'Technological and Economic Factors Determining ICT Level: Evidence from Rural Micro-Businesses in Democratic Republic of Congo', Journal of International Development. John Wiley \& Sons, Ltd, 30(1), pp. 118-133. doi: 10.1002/jid.3281.

[15] Vanneschi, L. et al. (2018) 'An artificial intelligence system for predicting customer default in e-commerce', Expert Systems with Applications. Pergamon, 104, pp. 1-21. doi: 10.1016/J.ESWA.2018.03.025. 